\title{
A UMBANDA EM RONDÔNIA ${ }^{1}$
}

Marta Valéria de Lima²

\section{RESUMO}

Este texto discute o processo de umbandização na região amazônica e sua relação com o declínio do Tambor de Mina, uma religião do universo afro-amazônico que, até a década de 1970, detinha a hegemonia no campo das religiões afro-brasileiras do Território Federal de Rondônia. Para estudar o tema elegemos como objeto de investigação a história da inserção e expansão da Umbanda nesse território e o estudo da conexão da mesma com a política partidária. Para alcançar os objetivos foi reconstituída a história do Terreiro de São Sebastião e analisada a relação desta com a fundação da Federação Espírita Umbandista de Rondônia - FEUR. Constatou-se que os projetos de integração nacional e as políticas desenvolvimentistas do Governo Federal contribuíram para a inserção da Umbanda na região e que o novo modelo religioso preservou elementos rituais do Tambor de Mina, o que favoreceu sua popularização em Rondônia.

\section{PALAVRAS-CHAVE}

Umbanda. Amazônia. Rondônia. Terreiro de São Sebastião.

\section{INTRODUÇÃO}

Na obra O reino dos mestres: a tradição da jurema na umbanda nordestina, Luiz Assunção (2006) oferece uma síntese que abrange várias concepções teóricas e definições de Umbanda contidas na literatura acadêmica nacional. Eis como ele a define e explica:

\begin{abstract}
A Umbanda é uma religião de possessão na qual a comunicação entre as entidades espirituais e os homens se dá por meio do transe. É considerada uma religião brasileira (Concone, 1987) por expressar em sua ideologia o nacionalismo e o mito das três matrizes culturais formadoras da identidade cultural brasileira. A umbanda é o resultado de um processo de reelaboração de elementos simbólicos de várias religiões que em uma determinada conjuntura histórica adquirem novos significados. Assim, dos candomblés e dos cultos bantos reorganiza-se o culto aos orixás; das religiões indígenas são incorporados os elementos de sua religiosidade e constrói-se uma imagem do índio expressa pela entidade do caboclo; do catolicismo popular, o ritmo dos cânticos, as rezas, a veneração aos santos católicos; do kardecismo, o discurso científico, a crença na reencarnação e a evolução espiritual (ASSUNÇÃO, 2006, p.103).
\end{abstract}

As primeiras formas de culto desse modelo religioso se visibilizaram na região amazônica na década de 1960, no contexto de implantação das políticas desenvolvimentistas e de modernização dessa região pelo Governo Federal. Foi justamente na década seguinte, durante a fase de execução dos Projetos de Assentamentos Dirigidos (PADs) e dos Projetos Integrados de Colonização (PICs) que a Umbanda se enraizou e se expandiu em Rondônia. Graças aos impactos das políticas modernizadoras do Governo Federal, o auge do desenvolvimento dessa religião acompanhou o ingresso de dezenas de centenas de migrantes nesse território e a elevação dos índices de crescimento demográfico na cidade de Porto Velho, onde foi fundado o primeiro espaço religioso socialmente reconhecido como de Umbanda, o Terreiro de São Sebastião (LIMA, 2001). De acordo com os dados obtidos em fontes impressas e orais, e também nos anuários estatísticos do Serviço de Estatística Demográfica, Moral e Política (posteriormente denominado IBGE), até essa década não havia espaços de cultos dedicados à Umbanda em Rondônia.

Essa religião alterou significativamente o curso histórico da vida social de uma parcela não desprezível da população rondoniense, então majoritariamente católica, mas permeável à adesão e à assimilação de outras práticas religiosas. Além disso, localmente predominava entre os adeptos das religiões de matrizes africanas a adoção de práticas religiosas identificadas como Tambor de Mina.

O objetivo deste texto é discorrer sobre o processo de implantação e expansão da Umbanda em Rondônia e discutir sobre a umbandizaçãodas práticas religiosas de matriz africana nesse estado

1 Este texto foi escrito no âmbito da pesquisa de doutorado da autora, tendo sido originalmente apresentado no XXVIII Simpósio Nacional da Anpuh, na cidade de Florianópolis (Santa Catarina, Brasil), no período de 27 a 31 de julho de 2015.

2 Doutora em História pela Universidad Pablo de Olavide, Sevilla, Espanha e Professora da Universidade Federal de Rondônia (UNIR). 
do Brasil. Portanto, nos itens a seguir iremos apresentare discutir a história da sua inserção e expansão em Rondônia, conforme narrada pela memória oral, pelas fontes impressas nos jornais e pela bibliografia regional. Mas antes, faremos uma rápida incursão em algumas explicações teóricasa respeito do fenômeno daumbandização na região amazônica.

\section{A UMBANDIZAÇÃO DA AMAZÔNIA: APORTES TEÓRICOS}

De um modo geral os estudos sobre a Umbanda foram influenciados por duas linhas de interpretação: A teoria da Integração, iniciada com os estudos de Roger Bastide (1989) e continuada por seu discípulo Renato Ortiz (1978) e a teoria dos polos, que foi elaborada por Cândido Procópio Ferreira de Camargo (1961). A teoria da integração analisa o fenômeno do aparecimento e expansão da Umbanda desde a perspectiva do projeto político de construção da nação brasileira pelo Estado. A teoria dos polos a analisa a partir da constituição do campo religioso afro-brasileiro tomando em consideração a sua estrutura e características internas.

O primeiro espaço ritual reconhecido e legitimado pelos estudiosos como de Umbanda surgiu no Rio de Janeiro na década de 1920. De acordo com Patrícia Birman (1985, p.95), após a Segunda Guerra Mundial a Umbanda adquiriu um caráter nacional, fato que é atribuído à liberação política do país com o fim do Estado Novo, às federações de cultos afro-brasileiros, ao acesso aos meios de comunicação de massa, em cujas atividades a Umbanda aparecia como opção religiosa no contexto das cidades do centro-sul brasileiro. Lísias Nogueira Negrão (1996) constatou a grande influência do Rio de Janeiro na estruturação e na difusão dos rituais de Umbanda em São Paulo. Enquanto nós, baseados no material empírico extraído de textos publicados pela imprensa rondoniense, constatamos a influencia de São Paulo na estruturação e na difusão desses rituais em Rondônia (LIMA, 2013).

Chester Gabriel e Yoshiaki Furuya relacionam a expansão da Umbanda na Amazônia ao avanço da política desenvolvimentista, pois a mesma acontece a partir da década de 1960, quando foi implantada uma vasta política modernizante que gestou uma série de transformações socioeconômicas e configurou o quadro de desenvolvimento urbano e de industrialização dessa região brasileira. No caso de Manaus (AM) isto ocorreu com a implantação da Zona Franca.

Chester Gabriel (1985, pp.158-159) não analisou o movimento de umbandização da Amazônia somente como resultado do processo de urbanização, como aconteceu com os primeiros teóricos da Umbanda ao estudarem o seu desenvolvimento no sul do país (BASTIDE, 1989; ORTIZ, 1978; BROWN, 1985). Ele defendeu a tese de que o transe teve um papel central para a sua difusão e assimilação na região amazônica. $\mathrm{Na}$ opinião dele o transe é o elemento comum entre a Umbanda e os cultos regionais e foi o que permitiu o jogo de relações e de comunicação entre os diversos sistemas religiosos, contribuindo, inclusive, para a continuidade dos cultos anteriores à chegada da Umbanda. Essa foi a explicação encontrada por ele para a rápida difusão desse sistema religioso em Manaus, pois, de acordo com os resultados da sua pesquisa, o transe possibilitou a introdução do ritual e das explicações umbandistas nas práticas de culto misto e, por outro lado, preparou o caminho para uma variedade ainda maior de cultos agrupados sob o nome Umbanda (GABRIEL, 1985, pp.104-105).

Igualmente Yoshiaki Furuya, que analisou a inserção e expansão da Umbanda na Amazônia, mas com o foco da pesquisa no Pará, afirmou que o sistema religioso africano oriundo do Maranhão (comumente denominado Tambor de Mina) incorporou a pajelança indígena local e ampliou o seu panteão de entidades espirituais. Ele também mencionou que "a Umbanda reformulou o mapa dos cultos afro-brasileiros em cada região do país, ao mesmo tempo em que, em vários sentidos, tem ocupado uma posição de religião nacional" (FURUYA, 1994, p. 12).

Embora Yoshiaki Furuyatenha considerado que a industrialização, urbanização e um- 
bandização estão conectadas, avaliou que esses não são fatores determinantes para a sua expansão na Amazônia. Sem negar o importante papel exercido pela circulação de coisas e de pessoas com a construção das estradas que ligam a Amazônia ao sul do país, afirmou haver outros fatores que precederam as mudanças socioeconômicas. Deste modo, rejeitou a hipótese de que a Umbanda se disseminou com a chegada dos sulistas na região amazônica. Em sua opinião as federações de culto tiveram um papel importante no processo de umbandização, pois elas atuaram positivamente na promoção desse processo. Yoshiaki Furuyatambém considerou que as relações entre as federações e a política local e nacional tiveram um papel importante na difusão da Umbanda. Ele viu nisso um circuito para a política nacional (FURUYA, 1994, pp. 46-48). Assim, argumentou que a umbandização da Amazônia precisava ser compreendida "antes de mais nada como um processo que vem se inserido na "ideologia do Estado brasileiro", a qual está por sua vez nitidamente representada na cosmologia umbandista” (FURUYA, 1994, p. 48). Ele ressaltou ainda que o movimento de federalização da Umbanda, ou seja, de unificação ritual e doutrinária dessa religião, se espalhou na região na década de 1960, contribuindo ainda mais para a expansão dos grupos de Umbanda (FURUYA, 1994, p. 34).

Yoshiaki Furuya viu o processo de umbandização da Amazônia como um movimento de mão dupla, pois afirmou que ao penetrar nas religiões afro-amazônicas, a Umbanda do sul se amazonižou. "O resultado é que apareceu uma situação em que as tradições mais antigas foram preservadas sob o nome de Umbanda ou foram reinterpretadas dentro do quadro referencial da Umbanda" (FURUYA, 1994, p. 48).

Feitas tais considerações, no item a seguir narraremos sobre a presença da Umbanda em Rondônia. Com isso esperamos que sejam respondidas as seguintes questões: como se deu a inserção desse modelo religioso em Rondônia? Quais eram as suas características? Quais foram os seus agentes sociais e quais foram os seus efeitos na sociedade e cultura local?

\section{HISTÓRIA DA UMBANDA EM RONDÔNIA}

Até onde se sabe Rondônia não possui uma base de identidade religiosa de terreiros de matriz africana assentada na história de populações escravas de seu antigo território e nem uma tradição de lideranças africanas na história da fundação e direção dos espaços de cultos afro-brasileiros. A memória social informa que o primeiro terreiro de Rondônia foi fundado por volta do ano de 1917 por populações de migrantesafrodescendentes oriundos dos Estados do Maranhão, do Piauí e do Pará. O terreiro fundado adotava a religião chamada Tambor de Mina e recebeu o nome de Recreio de Yemanjá (LIMA, 2001).

A Umbanda entrou em Rondônia pelas rotas do rio Madeira. Segundo os relatos, o modelo que se estabeleceu foi trazido de Manaus pelo sacerdote Celso Guimarães de Lima em 1964. Conforme a memória oral a mesma foi organizada quando ele fundou o Centro de Umbanda de São Sebastião, mais conhecido como Terreiro de São Sebastião. Esse terreiro foi edificado na segunda metade da década de 1960, à Rua Jaci Paraná, número 1492, entre as ruas Salgado Filho e João Goulart, no Bairro Mato Grosso. Para organizá-lo Celso Guimarães contou com a ajuda material e o apoio espiritual de Hilton da Veiga Monteiro, um migrante que veio de Manaus para Porto Velho em 1965 e que mais tarde ficou conhecido como Pai Hilton, sendo também chamado Hilton de Ogum. Hilton da Veiga Monteiro era filho de santo de Celso Guimarães e foi co-dirigente do terreiro, onde exerceu a função de pai pequeno. Outro indivíduo que auxiliou Celso Guimarães na fundação do Centro de Umbanda São Sebastiãofoi Celestino Pereira da Silva, o qual exerceu o cargo de Presidente (ALTO MADEIRA, 21e 22/01/1979, p. 3).

\section{CARACTERÍSTICAS DO PRIMEIRO TERREIRO DE UMBANDA EM RONDÔNIA}

Em depoimento à pesquisadora Maria Cristiane Pereira de Souza (2008, p. 60) a curan- 
deira Raimunda Oliveira, mais conhecida como Raimunda Paeira, também chamada de Paeirinha, que foi sacerdotisa de Umbanda eocupou o cargo de mãe pequena (sacerdotisa auxiliar, uma espécie de vice-dirigente) no Terreiro de São Sebastião, declarou que o mesmo “Era um Centro bem pequeninho”. Não temos, entretanto, descrições pormenorizadas sobre a organização espacial desse terreiro. O que sabemos é que os seus proprietários e dirigentes foram amantes das artes e que o salão de danças contou com algumas telas de Afonso Ligório, um artista plástico da região que sempre se dedicou a fazer registros sobre a cultura religiosa popular em seus trabalhos. Nas suas telas e afrescos Afonso Ligório pintava santos, caboclos, orixás e encantados que frequentavam o imaginário amazônico e também os terreiros durante os transes dos iniciados. Outro detalhe importante: a sacerdotisa de Candomblé, Wilma Inês de França Araújo/ Wilma de Oyá, falou-nos em entrevista que esse terreiro foi o primeiro de Porto Velho (capital de Rondônia), a ter um letreiro na entrada do salão de danças informando a sua identidade: Centro de Umbanda São Sebastião. De acordo com ela, anteriormente não se usavaesse tipo de identificação nos locais de culto.

No processo de estruturação e funcionamento do terreiro de São Sebastião houve renovação de suas práticas rituais e inovação do ambiente de culto. No ano de 1979 o salão de danças foi adornado com telas que apresentavam as imagens dos orixás: Iansã, Iemanjá, Ogum, Nanã Burucú e Oxumaré (ALTO MADEIRA, 21 e 22/01/1979, p. 3). Todas elas representavam entidades que visitavam o terreiro no corpo de alguns adeptos afiliados quando esses entravam em transe durante os ritos. Isso também era novidade. Naquela época a representação simbólica dos orixás não era comum nos espaços de culto de Rondônia, já que até o final da década de 1970 o Candomblé era uma modalidade religiosa quase que completamente estranha à realidade e cultura local.

O terreiro de São Sebastião era dotado de características religiosas sincréticas. Reconhecido pela memória coletiva como o primeiro local de realização de cultos de Umbanda em Rondônia, as suas práticas rituais também são identificados ao Tambor de Mina. Segundo declaração de Raimunda Paeira, “era Tambor, Umbanda, misturado" (SOUZA, 2008, p. 60). Obtivemos a mesma informação com vários sacerdotes com os quais conversamos ao decorrer da pesquisa de campo, em 2011. A condição mista da identidade religiosa do Terreiro de São Sebastião pode ser atribuída ao fato de seus dirigentes terem participado de rituais de Tambor de Mina tanto em Manaus (AM) quanto em Belém (PA), bem como deles haverem frequentado os terreiros de Tambor de Mina da cidade de Porto Velho, nos quais dançavam e eram possuídos por entidades espirituais dessa modalidade religiosa.

Há informações de que no princípio da adolescência Celso Guimarães costumava ir dançar no Barracão de Santa Bárbara (LIMA, 2001, p.101). Por sua vez, em entrevista, Hilton da Veiga Monteiro afirmou que, ao chegar a Rondônia, foi recebido no Terreiro de Samburucú pela venerada entidade Jarina incorporada na sacerdotisa Ceci Lopes Bitencourt (Chica Macaxeira). Disseainda que teve a honra de ser levado para o quarto onde era cultuada a prestigiada entidade da mina-encantaria conhecida pelo nome de Seu Jurema (Joaquim da Costa Jurema), que igualmente o recebeu. Ele também mencionou que Celso Guimarães de Lima, assim como ele próprio, dançou nesse terreiro por certo tempo (dois ou três anos).

Apesar disto, há que se levar em conta que o sincretismo dos ritos do Terreiro de São Sebastião pode ser atribuído a uma tendência cultural presente nos cultos do interior do Maranhão (Codó, Cururupú, Santo Antônio) e que se espalhou por toda a região amazônica com os fluxos migratórios maranhenses a partir do I Ciclo da Borracha, no final do Século XIX; e à abertura de terreiros de Tambor de Mina no início do Século XX por alguns desses migrantes, nas suas principais capitais (Belém, Manaus, Porto Velho), conforme atesta a literatura especializada (GABRIEL, 1980; FURUYA, 1984; FERRETTI, 2001). De acordo com registros da memória oral e documental, esse espaço de culto se manteve como único terreiro de Umbanda da localidade de Porto Velho até meados da década de 1970, 
quando outros sacerdotes que já possuíam seus próprios locais de culto os ampliaram e requereram em cartórios a sua inscrição como Centros de Umbanda. É importante frisar que esses centros, também conhecidos como tendas, tanto poderiam ser uma pequena ou grande seara como, de fato, um terreiro no sentido com o qual esse conceito tem sido socialmente compreendido no Brasil ao se fazer menção aos espaços de culto das religiões afro-brasileiras.

O Terreiro de São Sebastião teve um rápido crescimento em número de adesão às suas práticas e, na década de 1970, o número de pessoas afiliadasera grande. O terreiro também gozou de grande popularidade na sociedade e teve bastante espaço na mídia local. Entre as décadas de 1970 e 1980 , as festividades promovidas nele eram divulgadas pela imprensa escrita. Várias notícias foram publicadas a respeito das mesmas nos jornais de grande circulação de Rondônia: Alto Madeira, O Guaporé e Tribuna. A sacerdotisa Maria do Carmo Sampaio Pinto/Dona Carmita, declarou que o Terreiro de São Sebastião cresceu e se tornou o "batuque" mais famoso de Porto Velho, e também o maior em número de afiliados, ainda nos primeiros anos da década de 1970 (LIMA, 2001, p.102).

\section{CONTRIBUIÇÕES DO TERREIRO DE SÃO SEBASTIÃO PARA O CAMPO RELIGIOSO DE RONDÔNIA}

Estudando a história do Terreiro de São Sebastião observamos que a urdidura do campo religioso afro-brasileiro de Rondônia teve nele um polo de contato entre as suas várias extremidades: foi elo de transição do Tambor de Mina para a Umbanda e dessa para o Candomblé ao unir as práticas religiosas do modelo tido nacionalmente como mais tradicional (o Candomblé) às do mais moderno (a Umbanda). Ele foi, também, um espaço de culto que revolucionou as práticas religiosas da cidade de Porto Velho e, por extensão de Rondônia, inovando o modo de efetuar os ritos públicos, e de incorporar ao panteão sagrado entidades que anteriormente eram desconhecidas da comunidade religiosa de Rondônia, como a prestigiada entidade da Umbanda Seu Sete da Lira, por exemplo. Outra inovação foi paramentar os filhos de santo que incorporavam com as entidades africanas ao estilo de tradicionais terreiros de Candomblé da Bahia e do Rio de Janeiro.

Além de tudo isso, do interior desse terreiro surgiu algumas das mais importantes lideranças religiosas das comunidades e grupos de cultos afro-brasileiros de Rondônia, dentre as quais são lembradas: José Ribamar Vieira/Zé de Ubirajara, Julieta Hóstia de Jesus Ribeiro/Mãe Hóstia, Raimunda Pereira/Raimunda Paeira, Raimunda Faustino, Osvaldina, Marcelina Figueiredo, Ozerina, Alzerina Amorim Sobrinho, Eronilde, Adeljacir Ribeiro Ferreira/Pai Jacir, Marli Auxiliadora Ribeiro/Mãe Marli. Todas essas pessoas foram iniciadas na Umbanda por Celso Guimarães e exerceram/exercem funções sacerdotais.

Há pouquíssimos sacerdotes que foram iniciados nas religiões afro-brasileiras na década de 1970 que não frequentaram o Terreiro de São Sebastião, sejam como seus afiliados sejam como meros dançantes sem qualquer vínculo de feitura no mesmo. Dentre as pessoas que frequentaram o terreiro por vários anos como dançantes, mas não como iniciados, são lembradas: Maria de Fátima Sampaio/Fátima de Oyá e Wilma Inês de França Araújo/Wilma de Iansã (posteriormente denominada Wilma de $O y a$ ), sacerdotisas de grande prestígio social e chefes de terreiro muito respeitadas entre os adeptos das religiões afro-brasileiras de Porto Velho.

No Terreiro de São Sebastião também surgiram sacerdotes que foram iniciados no Candomblé da tradição angola pelas mãos do sacerdote Hilton da Veiga Monteiro. Posteriormente alguns desses sacerdotes, e também outros adeptos da Umbanda e do candomblé angola, foram iniciados no Candomblé da tradição queto pelo mesmo Hilton da Veiga Monteiro. Esse foi o caso da sacerdotisa Jacira Ribeiro Ferreira/Mãe Jacira e de Júlia Moraes dos Santos/Júlia de Ogum. Isso aconteceu após ele terpassado pelos ritos de confirmação e consagração nessa nova modalidade religiosasob a orientação de José Nilton Viana dos Reis/Torodé, sacerdote dessa nação. Pelas mãos de José Nilton Viana dos Reis/Torodé surgiram 
outros sacerdotes dentre os afiliados e ex-afiliados do Terreiro de São Sebastião. Do mesmo modo houve pessoas desse mesmo terreiro que se iniciaram no Candomblé jeje com o sacerdote Wilson Rodrigues, como foi o caso de Raimunda Paeira.

Essa capacidade dos dirigentes do Terreiro de São Sebastião de atrair pessoas e de influenciar as suas escolhas religiosas foi tão significativa que mesmo se não foram eles os promotores da entrada de novas religiões em Rondônia, certamente proporcionaram o ingresso de um grande número de pessoas nas mesmas. Neste sentido, tanto a difusão da Umbanda quanto a do Candomblé teve no Terreiro de São Sebastião um importante polo de irradiação.

\section{TERREIRO DE SÃO SEBASTIÃO E POLÍTICA PARTIDÁRIA}

Na década de 1970 o Terreiro de São Sebastião aparece na mídia como local de reunião de umbandistas que se lançavam como candidatos na política eleitoreira. Em 1976, o candidato a vereador pelo Movimento Democrático Brasileiro - MDB, Enjolras Araújo Veloso procurou apoio à sua candidatura junto aos umbandistas de Porto Velho. Conforme notícia publicada nos dias 12 e 13 de setembro pelo jornal O Guaporé (1976, p.2), durante as atividades de sua campanha ele se reuniu com eleitores "na residência do Sr. Celso, onde funciona o batuque do mesmo". De acordo com o periódico a campanha do candidato do partido de oposição "se cimentou ao ambiente dos seus irmãos umbandistas da cidade" (O GUAPORÉ, 21/11/1976, p.3). E, conforme o mesmo periódico, Enjolras de Araújo Veloso não foi o único político a buscar o apoio dos umbandistas. Naquela mesma eleição houve um candidato da Aliança Renovadora Nacional - ARENA (partido da situação), que disputou com ele os votos desses eleitores.

O Terreiro de São Sebastião foi um espaço social importante na constituição do campo de disputas pelo poder político na sociedade rondoniense. $O$ terreiro foi também anfiteatro de rivalidades e de lutas políticas internas, bem como de organização institucional burocrática dos umbandistas. Nele aconteceram as primeiras conversas e reuniões para fundar uma entidade federativa de cultos afro-brasileiros em Rondônia e cuja finalidade seria a de defender os interesses do povo de santo (adeptos das religiões e religiosidades afro-brasileiras) junto aos órgãos públicos e à sociedade civil.

Os amazonenses Enjolras de Araújo Veloso e Carlos Alberto dos Santos/Carlos Melhoral, frequentadores do terreiro, unidos a outras lideranças sociais e políticas, gestaram a ideia de criação da Federaşão Espírita Umbandista de Rondônia - FEUR. Celso Guimarães de Lima usou a sua influência junto à comunidade religiosa para favorecer a iniciativa de organizar politicamente os terreiros e grupos de culto locais. Isso ampliou o seu prestigio junto à comunidade religiosa.

O Terreiro de São Sebastião deu sustentação à FEUR, ao reunir os “antigos” religiosos (os religiosos mais idosos e os adeptos do Tambor de Mina) e os "novos" (os religiosos mais jovens e os adeptos da Umbanda) nos seus ritos de Umbanda e nas suas reuniões sociais e políticas. O movimento para a criação da FEUR e unificação do povo de santo de Rondônia aos movimentos de integração das religiões afro-brasileiras do resto do Brasil reforçou a popularidade do terreiro. Durante a década de 1970, ocorreram alguns encontros anuais dos umbandistas no Território de Rondônia, os chamados Encontros dos Orixás e Festa dos Orixás. Naquelas ocasiões o povo de santo se reunia no referido terreiro para realizar um ensaio geral dos cantos que seriam entoados nas celebrações que faziam parte da programação desses eventos.

Todos os fatos mencionados provocaram mudanças no campo religioso afro-brasileiro de Rondônia e produziram alterações nos seus quadros de hegemonia. Os dados coletados não dão margens a dúvidas de que Celso Guimarães de Lima e Carlos Alberto dos Santos/Carlos Melhoral foram agentes religiosos importantes nesse processo, pois ambos acionaram mudanças radicais na reestruturação do campo religioso local em direção à Umbanda e ao Candomblé. Houve fatores internos e externos 
que contribuíram para os sucessos de suas respectivas inserções sociais e para as transformações do campo religioso afro-brasileiro de Rondônia. Dentre tais fatores, e dada a impossibilidade de explicar outros motivos dentro dos limites deste trabalho, selecionamos: a capacidade agregadora de Celso Guimarães de Lima, a atuação da FEUR, o declínio dos terreiros mais antigos e a semelhança estrutural entre o Tambor de Mina e a Umbanda.

\section{TERREIRO DE SÃO SEBASTIÃO E EXPANSÃO DA UMBANDA}

A popularidade do Terreiro de São Sebastião pode ser atribuída ao carisma e à competência religiosa dos seus dirigentes, tidos como grandes sacerdotes pela comunidade de adeptos dos cultos afro-brasileiros de Rondônia. Outra situação que levou a isso foi o fato de serem os mesmos exímios mediadores sociais. Mas seguramente não foram esses os únicos motivos. Como mencionamos, dentre as causas que favoreceram a expansão da Umbanda em Rondônia encontram-se: a atuação da FEUR, odeclínio dos terreiros mais antigos e semelhanças estruturais entre o Tambor de Mina e a Umbanda.

A FEUR desempenhou o papel de congregar em seu interior um conjunto de importantes autoridades religiosas locais e nacionais. Ela atraiu para o seu corpo de visitantes grandes autoridades religiosas da Umbanda e do Candomblé, tanto da região amazônica quanto de outras regiões do Brasil. José Ribamar de Castro (MA), Nenê Gaya (PA), Jamil Rachid (SP), Moab Caldas (RG), José Paiva de Oliveira (GO) e Pai Jaú (RJ) são alguns dos sacerdotes conhecidos regional e nacionalmente que participaram de atividades promovidas por essa entidade (LIMA, 2013, pp. 456-499 e pp.564-569). Assim, a FEUR agregou os diferentes grupos religiosos locais e os conectou aos movimentos de unificação religiosa em curso no país, unindo-os e reunindo-os em nome da Umbanda a sacerdotes e terreiros de renome, alterando assim o eixo de influência do poder sacerdotal e de representação simbólica do Norte para o Sul do Brasil. Esses fatos corroboram a tese de Yoshiaki Furuya (1994) a respeito do papel das federações no processo de umbandização da Amazônia e permitem-nos perceber a importância política e estratégica das mesmas.

Também contribuíram para a expansão da Umbanda e o declínio dos terreiros mais antigos os seguintes fatores: falecimento de Esperança Rita da Silva (1972?), fundadora do Tambor de Mina em Rondônia.Esse acontecimento favoreceu o crescimento do Terreiro de São Sebastião, porque após o falecimento dessa sacerdotisa houve uma profunda crise sucessória que culminou com a suspensão das funções religiosas do terreiro dirigido por ela e com o fechamento do mesmo. O terreiro Recreio de Yemanjá, que a partir da década de 1940 ficou conhecido pelo nome de Barracão de Santa Bárbara, e que pertencia a ela, só foi reaberto cerca de dois a três anos depois - embora o seu sucessor, Albertino Barbosa da Silva, continuasse a exercer as funções sacerdotais (LIMA, 2001). O bairro onde o terreiro foi reconstruído era de acesso mais difícil e também era mais violento por ser uma zona de disputas fundiárias entre os ocupantes dos lotes circundantes - os quais haviam sido "invadidos" - e aquele que se identificava como o proprietário “legal” (ALTO MADEIRA, 11/11/1991, p. 3). Além disso, a área era alagadiça, tornando difícil o tráfego de veículos e de pessoas durante a estação das chuvas; e as "ruas" (se é que assim podem ser chamados os locais de transito) não eram pavimentadas, eram caminhos com mato que davam acesso às casas. Tudo isto desestimulava a frequência ao terreiro, o que levou adeptos e frequentadores a buscarem novos espaços de culto. O Terreiro de São Sebastião foi uma opção disponível para os mesmos.

Essa situação indica que há uma expressiva similaridade nos processos históricos dos cultos afro-brasileiros na região amazônica. Segundo Chester Gabriel (1985, p.158) no início do ano de 1977, quando viajou a Manaus para dar continuidade às suas pesquisas observou que houve uma deterioração geral das atividades de sessões de cultosque havia conhecido em 1973. Ele afirmou que os batuques funcionavam de modo precário, as cerimônias ocorriam esporadicamente, e os edifícios em 
geral desapareceram ou estavam em querelas sucessórias. Ele também mencionou que houve centros que fecharam, e mães de santo que faleceram sem deixar sucessores treinados na tradição, restando o mérito de atendimento nas bancas de cura/mesinhas (espaços privados onde se realizavarituais com ou sem incorporação para cura de enfermidades). E assim, os batuques tinham suas funções estendidas aos centros e às mesinhas durante as festas, onde se passou a realizar danças. De acordo com ele, os centros (terreiros e outros espaços de culto) que permaneceram em funcionamento não deram continuidade ou completaram os rituais iniciados nas casas do Maranhão, ou de Belém e de outros locais de origem. Praticamente não houve formação oficial nos rituais. Quando surgiram novos terreiros, os médiuns das casas antigas foram participar dos seus rituais. Eles acabaram se submetendo às novas práticas.

Chester Gabriel afirmou que a situação descrita acima abriu caminho para o futuro ingresso da Umbanda no Estado do Amazonas, onde os novos cultos foram sendo incorporados aos seus antigos círculos de culto. Os terreiros, que até então funcionavam como espaços de cumprimento de "obrigaçoes" (rituais) e onde eram realizadas as danças festivas chamadas "brinquedos", pouco a pouco foram se tornando local onde também eram realizados "trabalhos" e "consultas", quando antes os mesmos eram restritos às bancas de cura e às searas. $\mathrm{Na}$ verdade, pelo que se pode apreender desses episódios, as bancas, por permitirem a recepção de dinheiro e outros bens em troca dos serviços prestados, abriram caminho ao ingresso da formação de uma clientela à qual se prestava "serviços" (como banhos de descarrego, jogos divinatórios, rituais de abertura de caminhos e outros) seguindo uma lógica de mercado.

Processo similar ao que foi descrito por Chester Gabriel ocorreu em Rondônia. Especialmente a partir da década de 1980, com a difusão do Candomblé e a instalação de novos espaços de culto. Outra circunstância que favoreceu a penetração da Umbanda no campo religioso de Rondônia foram as semelhanças estruturais entre o Tambor de Mina e a Umbanda. Tais semelhanças podem ser compreendidas a partir de dois ângulos: do Tambor de Mina para a Umbanda e dessa para o Tambor de Mina. Vejamos como isso se processava:

1) Semelhança entre os rituais de Umbanda do Norte com os rituais de Umbanda do Sul. Havia algumas semelhanças na forma de organização do culto e na filosofia dos ritos que eram praticados no Terreiro de São Sebastião com os ritos da Umbanda do Sudeste, tais como: a ênfase na caridade e na prática da cura; a quase ausência de ritos sacrificais com derramamento de sangue; a presença de imagens católicas no interior do terreiro; o transe de possessão com espíritos indígenas; e o culto aos exus (a principal entidade com a qual Celso Guimarães incorporava era Seu Sete da Encruzilhada da Lira).

2) Semelhança entre os rituais de Umbanda e os rituais de Tambor de Mina. Havia semelhanças estruturais entre o Tambor de Mina e a Umbanda praticada no Terreiro de São Sebastião. Portanto, não houve uma ruptura radical entre o modelo religioso que Celso Guimarães levou de Belém e de Manaus e o que era praticado pelo povo de santo de Rondônia. Inclusive, antigos adeptos do Tambor de Mina não recordam diferenças ritualísticas. Isto parece indicar que se as mesmas existiam não eram consideradas relevantes. Os rituais do Terreiro de São Sebastião foram descritos nas entrevistas que nos foram concedidas pelo sacerdote Hilton da Veiga Monteiro/Hilton de Ogum (2011) do seguinte modo:

Era uma Umbanda muito bonita. A Umbanda do Celso era no tambor. Num vejo aquele sangue que você falou. Tinha tudo isso, mas era pouquinho. Era pinto de primeira pena. Aqueles pintinhos assim, ó (fez uma demonstração do tamanho com o dedo polegar da mão direita sobre a primeira falange do indicador). Não era galo e nem frango, não. Era pinto mesmo. Hum, hum. Não tinha pombo. Nada disso, não (MONTEIRO, 26 de maio de 1911).

Nesse como em outros aspectos (cantos, danças, vestes, presença dos caboclos encantados e realização de procissões e ladainhas católicas em seus rituais) as práticas religiosas do Terreiro de São Sebastião guardavam semelhança com as do Tambor de Mina. 


\title{
CONCLUSÃO
}

As mudanças do campo religioso afro-brasileiro de Rondônia acompanharam os fluxos migratórios que resultaram das ações do Estado brasileiro na região, como foi o caso do Tambor de Mina, que chegou a essa área do país durante a construção da Estrada de Ferro Madeira Mamoré e o da Umbanda, que adentrou o mesmo território durante a fase de implantação das políticas desenvolvimentistase de integração nacional da Amazônia brasileira ao resto do país. Esses fatos indicam que cultura e política são faces de uma mesma moeda e que é importante estudar uma olhando para a outra.

Analisando os aspectos organizacionais do Terreiro de São Sebastião chegamos à conclusão de que a estrutura religiosa do mesmo foi relevante para a sua aceitação social e que foi graças a ela que o mesmo conquistou espaço social, já que o modelo religioso implantado se aproximava das práticas rituais da Umbanda sulista e não diferia, essencialmente, dos ritos de Tambor de Mina. Em vista disso o terreiro atraiu tanto os rondonienses como os migrantes amazônicos e, também, os nordestinos e sulistas mais afeitos à Umbanda.

Apesar da grande popularidade de que desfrutou e da sua indiscutível relevância na vida religiosa de Rondônia, o Terreiro de São Sebastião não teve vida muito longa. Em 1984, não sem grande pesar do povo de santo, as suas atividades foram encerradas. $\mathrm{O}$ terreiro deixou de funcionar após um período de decadência que foi sucedido da morte trágica de Celso Guimarães de Lima, seu fundador e dirigente.

\section{UMBANDA IN RONDÔNIA}

\begin{abstract}
This article discuss the umbandização process in the amazon region and its relation with the decline of Tambor de Mina, an African Amazon religion that was hegemonicamong theAfrican Brazilian religions in Rondônia territory until 1970. Tostudy the umbandização wechose as aninvestigation subject the history of the expansion and inclusion of Umbanda at theseterritory and its relation with the political parties. Toreach the objectives, were constructed the history of Terreiro de São Sebastião and analyzed its relation with the creation of Federação Espírita Umbandista de Rondônia - FEUR. We concluded that the Federal Government projects for national integration and the development policies helped the Umbanda integration at Rondônia, however the new religious model preserved ritual elements of Tambor de Minas, which helped the Umbanda popularization in Rondônia.
\end{abstract}

\section{KEYWORDS}

Umbanda. Amazon. Rondônia. Terreiro de São Sebastião.

\section{REFERENCIAS}

ARAÚJO, Wilma Inês de França. Sacerdotisa Wilma de Oyá. Porto Velho: 22 de mar. 2011. Entrevista concedida a Marta Valéria de Lima.

ASSUNÇÃO, L. O reino dos mestres: a tradição da jurema na Umbanda nordestina. Rio de Janeiro: Pallas, 2006. BASTIDE, R. As religiões africanas no Brasil. Trad. Maria Eloisa Capellato e Olívia Krähenbühl. $3^{a}$ ed., São Paulo: Pioneira, 1989.

BIRMAN, P. O que é umbanda. São Paulo: Abril Cultural: Brasiliense, 1985 (Coleção Primeiros Passos).

BROWN, D. Uma história da Umbanda no Rio. In: Umbanda e Política. Rio de Janeiro: Editora Marcos Zero, 1985, pp. 9-42 (Cadernos do ISER, n. 18).

CACCIATORE, O. G. Dicionário de cultos afro-brasileiros. 3a . ed., Rio de Janeiro: Forense-Universitária, 1988. CENTRO SÃO SEBASTIÃO FESTEJOU SEU SANTO PADROEIRO. Alto Madeira. Porto Velho, 21 e 22 jan. 1979. Ano LXI, n. 13.142, p. 3.

FERRETTI, M. Encantaria de "Barba Soeira": Codó, capital da magia negra? São Paulo: Siciliano, 2001.

FURUYA, Y. Umbandização dos cultos populares na Amazônia: a integração ao Brasil. Tradução de Ronan Alves Pereira. Senri Etnological Reports, n.1, 1994. Disponível em: http://goo.gl/X8lxDP. Acesso em: 15/dez.2015.

GABRIEL, C. E. Communications of the Spirits: umbanda, regional cults in Manaus and the dynamics of mediumistic trance. Thesis (Doctor), McGillUniversity, 1980. 
LIMA, M. V. Barracão de Santa Bárbara em Porto Velho-RO: mudanças e transformações das práticas rituais. 2001. 476 f. Dissertação (Mestrado em Antropologia). Programa de Pós-Graduação em Antropologia Cultural, Universidade Federal de Pernambuco - UFPE. Recife, 2001.

LIMA, M. V. Dos tambores de Averequete aos tambores de Oxalá. História de uma relação complexa: as religiões afro-brasileiras e a sociedade de Rondônia (1911-2011). Tese (Doutorado em História), Universidad Pablo de Olavide de Sevilla. Departamento de Geografía, Historia y Filosofia. Programa Oficial de Postgrado en Historia de América Latina. Mundos Indígenas, Sevilla (España), 2013.

MONTEIRO, Hilton da Veiga. Sacerdote Hilton de Ogum. Porto Velho: 26 de maio 2011. Entrevista concedida a Marta Valéria de Lima.

NEGRÃO, L. Entre a cruz e a encruzilhada: formação do campo umbandista em São Paulo. São Paulo: Editora da Universidade de São Paulo, 1996.

ORTIZ, R. A morte branca do feiticeiro negro: Umbanda e Sociedade. São Paulo: Brasiliense, 1978.

PANORAMA POLÍTICO: MDB COMEÇA PROPAGANDA. O Guaporé. Porto Velho, 12 e 13 set. 1976. Ano XXII, n. 6.867, p. 2.

PMDB ESQUECEU DIA DA MORTE DE AGENOR. Alto Madeira. Porto Velho, 11 nov. 1991. Ano LXV, n. 13.883 , p. 3.

REPÓRTER INFORMATIVO: DOIS CANDIDATOS DISPUTAM VOTOS UMBANDISTAS. O Guaporé. Porto Velho, 02 de nov. 1976. Ano XXII, n. 6.909, p. 3.

REPÓRTER INFORMATIVO: ENJOLRAS ARAUJO VELOSO, OUTRO NÃO FOI LÁ. O Guaporé. Porto Velho, 21 nov. 1976. Ano XXII, n. 6.924, p. 3.

SOUZA, M. C. P. S. (2008). A palavra e o lugar da cura: história oral com rezadeiras. Dissertação de Mestrado. Porto Velho: Programa de Pós-Graduação em Geografia - Universidade Federal de Rondônia, 2008. 